frequently have disabilities and handicaps in mobility and physical independence that are often untreated. The prompt recognition and rehabilitation of impairments of coordination, balance, fine motor and sensory function should prevent development of handicap in these patients.

Self-esteem, behavior, and concerns surrounding epilepsy in siblings of children with epilepsy were investigated by the Minnesota Epilepsy Group, St Paul, MN. (Mims J. I Child Neurol April 1997;12:187-192). Families of children with frequent seizures had significantly more stress, but no loss of self-esteem or socialization. The effects of epilepsy on the siblings of children with intractable seizures should receive further study.

\title{
ATTENTION DEFICIT HYPERACTIVITY DISORDER
}

\section{TWIN STUDIES OF ADHD}

Genetic and environmental contributions to the inattention and impulsivity-hyperactivity associated with ADHD in 576 twin boys, aged 11 and 12 years, participants in the Minnesota Twin Family Study, were estimated by teacher ratings and maternal interviews in a report from the Department of Psychology and the Institute of Human Genetics, University of Minnesota, Minneapolis. Univariate analyses of the teacher and maternal reports confirmed the importance of genetic factors in the mediation of both inattention and hyperactivity-impulsivity subtypes of ADHD. For both traits, the genetic factor was considerably higher for maternal reports, which suggests a rater bias. Environmental factors, shared or nonshared among family members, had lesser contributions to the etiology of ADHD, and shared environment affected only the teacher-rated inattention dimension. (Sherman DK, Iacono WG, McGue MK. Attention-deficit hyperactivity disorder dimensions: a twin study of inattention and impulsivity-hyperactivity. I Am Acad Child Adolesc Psychiatry June 1997;36:745-753). (Reprints: Dt lacono, Department of Psychology, University of Minnesota, Elliott Hall, 75 East River Road, Minneapolis, MN 55455).

COMMENT. Twin studies involving only males suggest that genetic factors are important in the cause of both inattention and hyperactivityimpulsivity subtypes of ADHD. Environmental experiences may exert a lesser effect on the development of these traits. The mode of inheritance of ADHD is undetermined, and results in affected girls, who characteristically demonstrate a greater degree of inattention, may be different. The inclusion of multiple informants, including psychologists and physicians, both neurologists and psychiatrists, would tend to lessen the influence of bias in studies involving ratings.

The extent of the genetic influence in the cause of ADHD varies according to the informant source. (Sherman DK, McGue MK, Iacono WG. Twin concordance for attention deficit hyperactivity disorder: a comparison of teachers' and mothers' reports. Am I Psychiatry April 1997;154:532-535). Environmental organic factors in etiology may receive greater emphasis and recognition among patients attending for pediatric neurology evaluation.

ADHD is a continuum, not a discrete entity, according to a large twin study, involving almost 2000 families recruited from the Australian MRC Twin Registry, and reported from the Prince of Wales Hospital, Randwick, NSW 
Australia. (Levy F et al. L Am Acad Child Adolesc Psychiatry June 1997;36:737744). ADHD may be explained as an inherited trait with liability and expression throughout the population, a deviance from an acceptable norm, and not restricted to an arbitrary number of symptoms or DSM criteria. The need for treatment including medication is relative, and dependent on multiple factors.

\section{METHYLPHENIDATE TREATMENT AND HOME BEHAVIOR}

Behavioral, situational, and temporal effects of treatment of ADHD with methylphenidate are reported in a study of 91 children receiving MPH (titrated to $0.7 \mathrm{mg} / \mathrm{kg}$ twice a day) or placebo for 4 months at the Hospital for Sick Children, Toronto, Canada. Symptoms of ADHD and comorbid oppositional behavior improved while at school, but not on returning home. Side effects were observed by the parents, not by teachers, and necessitated MPH withdrawal in 10\%; these included sadness, behavioral deterioration, irritability, withdrawal, lethargy, violent behavior, and mild mania. Anorexia, loss of weight gain (without effect on growth), and stomachache were the most common physiological side effects, and withdrawal, sadness, and crying, the most common affective side effects during MPH treatment. (Schachar RJ, Tannock R, Cunningham C, Corkum PV. Behavioral, situational, and temporal effects of treatment of ADHD with methylphenidate. I Am Acad Child Adolesc Psychiatry June 1997;36:754-763). (Reprints: Dr Schachar, Child Psychiatry Research Unit, The Hospital for Sick Children, 555 University Ave, Toronto, Ontario, Canada M5G $1 \times 8)$.

COMMENT. Methylphenidate administered twice daily benefits behavior and attention of ADHD children in the classroom but not in the home. Three times daily schedule of doses might facilitate completion of home work assignments and lead to improved parent-child relations. (see Ped Neur Briefs Nov 1996;10:82, for review of MPH dosing schedules and a report by Stein MA, Roizen NJ et al).

\section{DEGENERATIVE DISORDERS}

\section{GENETICS OF JUVENILE SPINAL MUSCULAR ATROPHY}

A 20-year-old female with difficulties in running and climbing stairs since age 10 and suspected of having spinal muscular atrophy (SMA) type III (Kugelberg-Welander disease) was diagnosed with GM2 gangliosidosis at the Department of Human Genetics, Sackler Faculty of Medicine, Tel Aviv University, and Sapir Medical Center, Kfar-Sava, Israel. Amyotrophy extended to the middle of the thighs in the lower limbs and had a distal glove distribution in the upper limbs. Deep tendon reflexes were present except for the ankle jerks. The survival motor neuron $(S M N)$ gene, lacking in SMA, showed no deletion. Biochemical studies showed increased accumulation of GM2 ganglioside and deficiency of hexosaminidase A (Hex A) activity in fibroblasts. In the HEXA gene, two mutations occurred, and the patient was a compound heterozygote, with each allele containing a different mutation. (Navon R, Khosravi R, Melki J et al. Juvenile-onset spinal muscular atrophy caused by compound heterozygosity for mutations in the HEXA gene. An n Neurol May 1997;41:631-638). Respond: Prof Navon, Molecular Genetics, Sapir Medical Center, Kfar-Sava 44281, Israel).

COMMENT. Progressive spinal muscular atrophy (SMA) type III 